\title{
Adherent Intrapericardial Teratoma: A Case Report
}

Neville A. G. Solomon - Swaminathan Vaidyanathan •

Kothai Sugumar · Musthafa Janeel

Received: June 29, 2018 / Published online: August 14, 2018

(C) The Author(s) 2018

\begin{abstract}
Intrapericardial teratomas are rare tumours arising from all three germinal layers. They are mostly benign, but can lead to life-threatening complications such as cardiac tamponade in newborns, so surgical excision of the tumour should be done as early as possible once the diagnosis is made. We report a neonate diagnosed with a large intrapericardial teratoma, managed surgically with the help of cardiopulmonary bypass.
\end{abstract}

Keywords: Cardiac tamponade; Foetal hydrops; Neonate; Teratoma; Tumour

\section{INTRODUCTION}

Teratomas are tumours originating from all three germinal layers, namely ectoderm, endoderm and mesoderm. The most common sites of teratomas are gonads and mediastinum.

Enhanced digital features To view enhanced digital features for this article go to https://doi.org/10.6084/ m9.figshare.6945347.

N. A. G. Solomon $(\varangle) \cdot$ S. Vaidyanathan .

K. Sugumar · M. Janeel

Department of Pediatric Cardiac Surgery, Apollo

Children's Hospital, Chennai, India

e-mail: nevillesolomon123@outlook.com
Intrapericardial teratomas are infrequent with a reported incidence of $0.05-0.15 \%$ in various case series published so far $[1,2]$. They can either be mature, which is benign with welldifferentiated tissues or immature, which can have malignancy potential [2]. Most commonly, they are mature with benign nature [2] We report a case of intrapericardial teratoma diagnosed antenatally and treated in the neonatal period with success.

This manuscript has been prepared in Compliance with Ethical Guidelines. Informed consent was obtained from the patient's parents for publication of the case report.

\section{CASE REPORT}

A 25-day-old female baby, born to a non-consanguineous couple of low socioeconomic status, was antenatally detected to have tumour in the mediastinum and referred to our hospital for further work-up. The baby was delivered by normal spontaneous vaginal delivery with a birth weight of $2.8 \mathrm{~kg}$. She was asymptomatic after birth until now. On examination, oxygen saturation was $98 \%$ in room air. Cardiovascular system examination was unremarkable. Chest X-ray showed cardiomegaly suggestive of pericardial effusion. Neonatal echocardiography (Fig. 1) and computed tomography (Fig. 2) of the chest identified a large intra-pericardial tumour $(5 \times 6 \mathrm{~cm})$, possibly teratoma, seen 


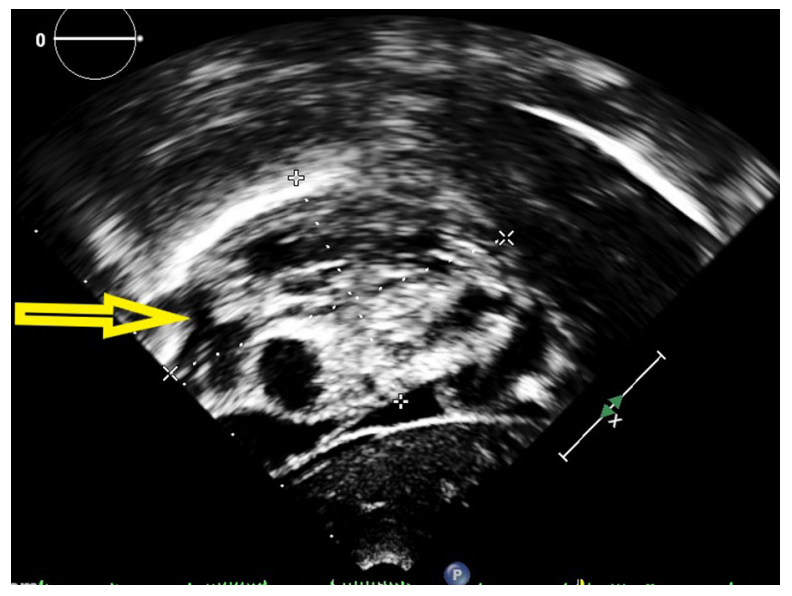

Fig. 1 Trans-thoracic echocardiography showing a large intrapericardial tumour

beside the right atrium and superior vena cava compressing the the right atrium and adherent to the ascending aorta with moderate pericardial effusion. After a multidisciplinary team meeting, the child was taken up for surgery.

Median sternotomy was done. Moderate pericardial effusion was drained. There was a large intrapericardial tumour attached to the ascending aorta (Fig. 3a). The tumour was seen to be arising from the tunica media of the ascending aorta to which it was densely adherent. It was, therefore, decided to electively perform cardiopulmonary bypass. Cardiopulmonary bypass was established with aortic and right atrium cannulation. The tumour was completely dissected from the aorta and was removed (Fig. 3b). There were tears at the site where the tumour was attached to the aorta. Those areas in the ascending aorta were repaired with 6-0 polypropelene sutures, thereby securing haemostasis. Histopathology examination of the mass confirmed the diagnosis of intrapericardial teratoma.

Post procedure, the patient's condition improved, and she was extubated on the 1st post-operative day and discharged on the 5 th postoperative day. The child was asymptomatic with normal echocardiogram at 1-month follow-up.

\section{DISCUSSION}

Neonatal intrapericardial teratoma can have varied presentation. At one end of the spectrum, they can be completely asymptomatic, to be detected either in routine prenatal ultrasonogram or in postnatal screening echocardiogram in neonatal period. Rychick et al. [3], reported six cases of true intrapericardial teratoma diagnosed antenatally. We also detected a mediastinal tumour in our patient's antenatal ultrasonogram, and the child was asymptomatic after birth. Diagnosis was confirmed in the neonatal screening echocardiogram.

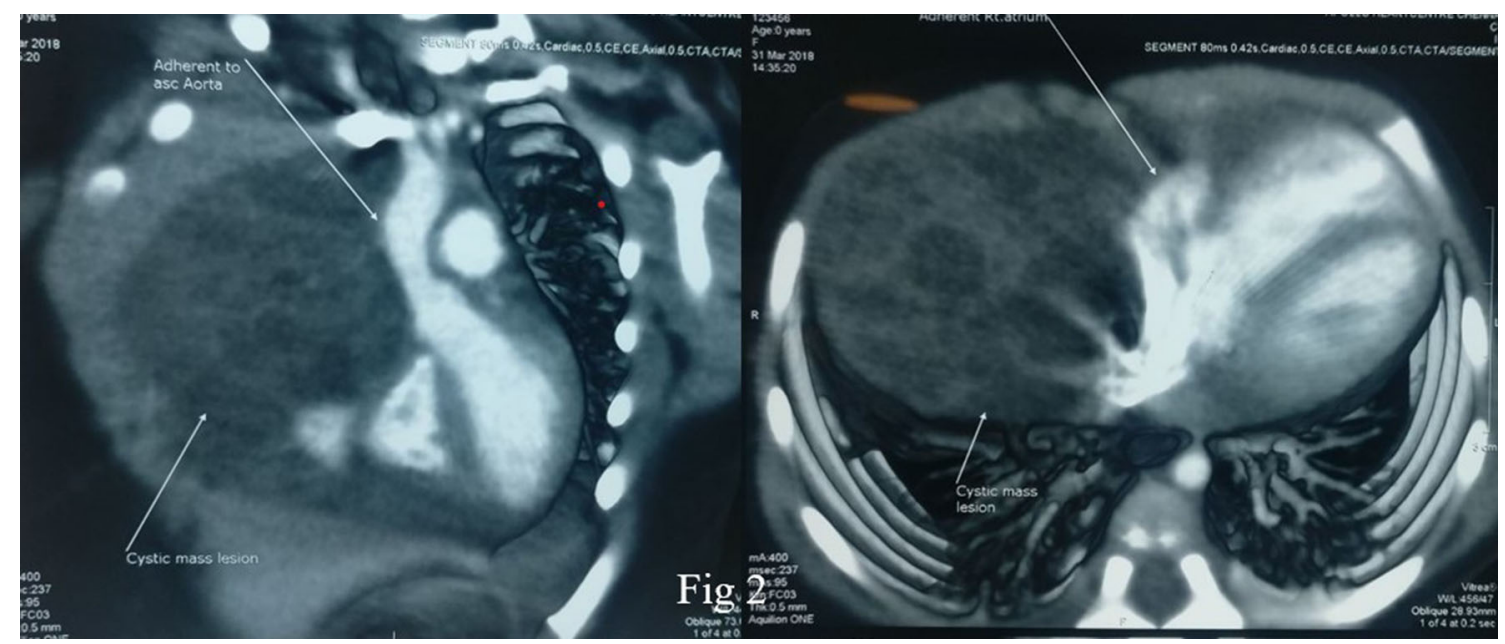

Fig. 2 Computed tomography of the chest showing an intrapericardial tumour adherent to the ascending aorta and right atrium 

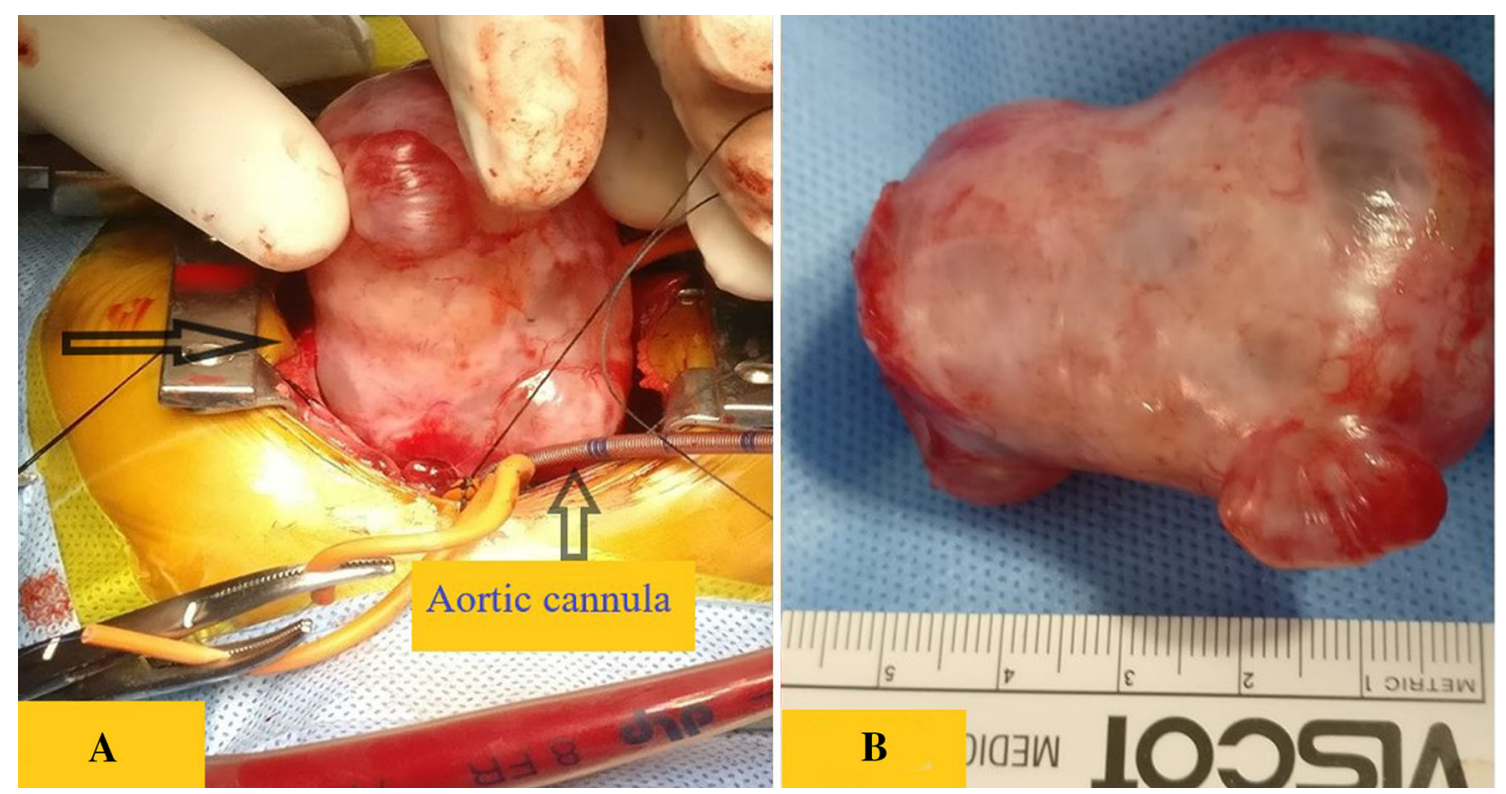

Fig. 3 a Intraoperative picture showing a large intrapericardial teratoma adherent tothe ascending aorta. b Picture showing the excised specimen

On the other end of the spectrum, they can present with fetal hydrops with pericardial effusion and stillbirth in the antenatal period $[4,5]$. Laquay et al. [5] reported two patients with intrapericardial teratoma developing pericardial effusion and hydrops fetalis, both of whom underwent pericardiocentesis to treat the hydrops fetalis. Similarly, also in the neonatal period, these patients are prone to developing pericardial effusion and cardiac tamponade [4]. They can also develop respiratory distress, cyanosis and congestive cardiac failure.

Diagnosis can be achieved antenatally by ultrasonogram, in the neonatal period by echocardiography. Computed tomography and magnetic resonance imaging can also aid in the diagnosis. Beghetti et al. [6] reported a 1-month-old boy presenting with signs of heart failure and tamponade. Echocardiography of that patient showed a complex mass with a large pericardial effusion compressing the heart; however, magnetic resonance imaging defined the relationship of the mass to the pericardium, myocardium, and great vessels. Histopathology examination of the resected specimen is considered the gold standard for confirmation of the diagnosis.
If diagnosed antenatally, some of these patients may need foetal pericardiocentesis in the antenatal period to prevent hydrops and foetal death, and those patients are advised for elective caesarean section since vaginal delivery can cause chest compression and cardiac obstruction, which can be fatal [5].

Nassr et al. [7] reported prenatal fluid drainage and other prenatal techniques have been utilized in the treatment and it is tolerated by most of the foetuses. Once diagnosed, surgical excision of the tumour in the neonatal period is the treatment of choice. Even asymptomatic patients warrant surgery because of risk of developing pericardial effusion and cardiac tamponade. Surgical resection can be done without the aid of cardiopulmonary bypass on many occasion. Tumour must be carefully dissected from the aorta without injuring it, once dissected it can be removed completely. Gobbi et al. [8], reported a 26-day-old neonate diagnosed with intrapericardial teratoma. The tumour was found to be attached to the anterior portion of the aortic root, adjacent pulmonary artery with focal adhesions to the myocardial wall of the right ventricle. They were able to excise the tumour along with a portion of 
adventitia of the ascending aorta without the need for cardiopulmonary bypass.

Through this case report, we need to stress upon the fact that intrapericardial tumours including teratomas may pose operative surprises, significant blood loss, technical misadventure and recurrence. Sometimes, as described in our case, the tumour may be densely adherent to the aorta, so we feel that we should have a lower threshold in performing cardiopulmonary bypass and removing the tumour completely. We feel that this is the main implication we would like to present through this case report for future therapy.

To conclude, neonatal intrapericardial teratoma should be managed aggressively with surgical excision as soon as the diagnosis is made.

\section{ACKNOWLEDGEMENTS}

Funding. No funding or sponsorship was received for this study or publication of this article.

Authorship. All named authors meet the International Committee of Medical Journal Editors (ICMJE) criteria for authorship for this article, take responsibility for the integrity of the work as a whole, and have given their approval for this version to be published.

Disclosures. Neville AG. Solomon, Swaminathan Vaidyanathan, Kothai Sugumar and Musthafa Janeel have nothing to disclose.

Compliance with Ethics Guidelines. Informed consent was obtained from the patient's parents for publication of this case report.

Open Access. This article is distributed under the terms of the Creative Commons
Attribution-NonCommercial 4.0 International License (http://creativecommons.org/licenses/ by-nc/4.0/), which permits any noncommercial use, distribution, and reproduction in any medium, provided you give appropriate credit to the original author(s) and the source, provide a link to the Creative Commons license, and indicate if changes were made.

\section{REFERENCES}

1. Malay J, Madhavi N, Satyavani A, Nishanth P, Manikyamba D. Intrapericardial immature teratoma with successful treatment in a neonate. Indian J Pediatr. 2014;81:1099-101.

2. MacKenzie $\mathrm{S}$, Loken $\mathrm{S}$, Kalia $\mathrm{N}$, et al. Intrapericardial teratoma in the perinatal period: case report and review of the literature. J Pediatr Surg. 2005;40:e13-8.

3. Rychik J, Khalek N, Gaynor JW, et al. Fetal intrapericardial teratoma: natural history and management including successful in utero surgery. Am J Obstet Gynecol. 2016;215:780-e1.

4. Iacona GM, Barber MA, Medina M, Abella R. Intrapericardial teratoma in a low birth weight preterm infant: a successful multidisciplinary approach. Interact Cardiovasc Thorac Sur. 2011;12:287-9.

5. Laquay N, Ghazouani S, Vaccaroni L, Vouhe P. Intrapericardial teratoma in newborn babies. Eur J Cardiothorac Surg. 2003;23:642-4.

6. Beghetti M, Prieditis M, Rebeyka IM, Mawson J. Intrapericardial teratoma. Circulation. 1998;97:1523-4.

7. Nassr AA, Shazly SA, Morris SA, et al. Prenatal management of fetal intrapericardial teratoma: a systematic review. Prenat Diagn. 2017;37:849-63.

8. Gobbi D, Rubino M, Chiandetti L, Zanon GF, Cecchetto G. Neonatal intrapericardial teratoma: a challenge for the pediatric surgeon. J Pediatr Surg. 2007;42:e3-6. 